\title{
OPTIMALISASI PENJUALAN KAIN ENDEK DENGAN METODE KARUSH-KUHN-TUCKER (KKT)
}

\author{
I Gede Aris Janova Putra ${ }^{\S 1}$, Ni Made Asih ${ }^{2}$, I Nyoman Widana ${ }^{3}$ \\ ${ }^{1}$ Jurusan Matematika, FMIPA - Universitas Udayana [Email: igajputra@ gmail.com] \\ ${ }^{2}$ Jurusan Matematika, FMIPA - Universitas Udayana [Email: asihmath77@gmail.com] \\ ${ }^{3}$ Jurusan Matematika, FMIPA - Universitas Udayana [Email: nwidana@yahoo.com] \\ ${ }^{\S}$ Corresponding Author
}

\begin{abstract}
This study is conducted to determine the optimal sales value of endek mastuli, endek rangrang, endek saraswati, endek gradasi, and endek alam in Novala Busana Shop and Trans Collection Shop in order to reache maximum advantage by using Karush-Kuhn-Tucker (KKT) method. Karush-Khun-Tucker method can be used to find the optimum solution of the function regardless of whether linear or nonlinear. In the workmanship is KKT method essentially involves the same steps as Lagrange method, from a Lagrangean to be able to calculate the critical points, finding all solutions $(x, \lambda)$, and calculate of the value $f(X)$. In this study, most of quarterly show that which must be sold are kind of endek mastuli in reaching the maximum benefit. For other kinds of endek is constantly provided but it is not as much as before. Suggested to the next research could involve more variated variable with more interesting cases.
\end{abstract}

Keywords: Karush-Khun-Tucker (KKT) method, Lagrangean, Optimization, Constraint, Endek

\section{PENDAHULUAN}

Setiap suatu usaha dagang, tentu hal yang ingin dicapai adalah memperoleh keuntungan yang maksimum. Pencapaian keuntungan maksimum dapat dicapai dengan suatu strategi penjualan. Salah satunya dalam ilmu matematika dapat diselesaikan dengan metode optimasi. Contoh kasus optimasi berkendala yaitu mengetahui jenis kain endek yang akan dijual untuk mencapai keuntungan yang maksimum.

Penelitian ini merupakan studi kasus penjualan kain endek pada dua toko yaitu toko Novala Busana dan toko Trans Collection. Adapun tujuan penelitian adalah mengetahui bentuk fungsi tujuan dan fungsi kendala yang diperoleh dari penjualan kain endek pada masing-masing toko, dan menentukan nilai optimal penjualan (proporsi suatu item yang dijual untuk mencapai keuntungan yang maksimum) yang diperoleh dengan metode Karush-Kuhn-Tucker (KKT).
Karush-Kuhn-Tucker pada tahun 1951 mengemukakan teknik optimasi yang dapat digunakan dalam pencarian titik optimum dari suatu fungsi yang berkendala tanpa memandang linier maupun nonlinier. Misalkan menghadapi masalah optimasi dalam bentuk:

Maksimumkan/Minimumkan:

$$
Z=f(X) \text { dengan } X=\left[x_{1}, \ldots, x_{n}\right]^{t}
$$

dengan kendala

$$
\begin{aligned}
& g_{i}(X) \leq 0 \text { atau } g_{i}(X) \geq 0 \text { dengan } \\
& i=1,2,3, \ldots, m \\
& X \geq 0 \\
& m \leq n \text { (banyak kendala lebih kecil atau } \\
& \text { sama dengan banyak variabel) }
\end{aligned}
$$

Pertama tuliskan kembali persyaratan yang tak negatif menjadi $-x_{1} \leq 0,-x_{2} \leq 0, \ldots,-x_{n} \leq 0$ sehingga himpunan kendalanya adalah $m+n$ persyaratan ketidaksamaan yang masing-masing dengan tanda lebih kecil dari pada atau sama dengan. Kemudian tambahkan variabel-variabel $x_{n+1}^{2}, x_{n+2}^{2}, \ldots, x_{2 n+m}^{2}$ berturut-turut pada ruas kiri dari kendala-kendala tadi, yang dengan 
demikian merubah setiap ketidaksamaan menjadi suatu kesamaan. Variabel slack yang ditambahkan berbentuk suku-suku kuadrat untuk menjamin bahwa mereka tak negatif [1]. Kemudian bentuk fungsi Lagrange:

$$
\begin{array}{r}
L \equiv f(X)-\sum_{i=1}^{m} \lambda_{i}\left[g_{i}(X)-x_{n+i}^{2}\right] \\
-\sum_{i=m+1}^{m+n} \lambda_{1}\left[-x_{i}+x_{n+i}^{2}\right]
\end{array}
$$

Fungsi Lagrange yang dibentuk adalah fungsi tujuan ditambahkan dengan total kendala. Untuk $\lambda_{1}, \lambda_{2}, \ldots, \lambda_{m+n}$ adalah pengali-pengali Lagrange [2].

Langkah terakhir selesaikan sistem persamaan:

$$
\begin{aligned}
& \frac{\partial L}{\partial x_{j}}=0 \quad(j=1,2, \ldots, 2 n+m) \\
& \frac{\partial L}{\partial \lambda_{i}}=0 \quad(i=1,2, \ldots, m+n) \\
& \lambda_{i} \geq 0 \quad(i=1,2, \ldots, m+n)
\end{aligned}
$$

Persamaan-persamaan (3), (4), dan (5) membentuk persyaratan Karush-Kuhn-Tucker (KKT) untuk maksimasi/minimasi program linier dan nonlinier [3]. Sehingga syarat Karush-Kuhn-Tucker (KKT) untuk kasus:

Minimumkan:

$$
f=f(X) \text { dengan } X=\left[x_{1}, \ldots, x_{n}\right]^{t}
$$

dengan kendala

$$
g_{j}(X) \leq 0 \text { dengan } j=1,2,3, \ldots, m
$$

dapat dinyatakan dalam satu set pernyataan sebagai berikut:

$$
\begin{array}{rc}
\frac{\partial f}{\partial x_{i}}+\sum_{j=1}^{m} \lambda_{j} \frac{g_{j}}{\partial x_{i}}=0, & (i=1,2 \ldots, n) \\
\lambda_{j} g_{j}=0, & (j=1,2 \ldots, m) \\
g_{j} \leq 0, & (j=1,2 \ldots, m) \\
\lambda_{j} \geq 0, & (j=1,2 \ldots, m)
\end{array}
$$

Catatan:

(i) Jika permasalahannya adalah memaksimumkan, maka $\lambda_{j} \leq 0$.

(ii) Jika kendalanya adalah $g_{j} \geq 0$, maka $\lambda_{j} \leq 0$.

(iii) Jika permasalahannya adalah memaksimumkan dan jika kendalanya adalah $g_{j} \geq 0$, maka $\lambda_{j} \geq 0$.

Nilai optimum (nilai maksimum atau nilai minimum) suatu fungsi multi variabel dengan kendala (constrains) berupa suatu persamaan adalah suatu kasus optimasi yang sering ditemukan dalam teori maksimum dan minimum yang terdapat dalam kalkulus. Adapun metode matematika yang dapat digunakan untuk kasus tersebut adalah metode pengali Lagrange [4]. Sedangkan untuk menentukan nilai optimum suatu fungsi matematika multi variabel dengan kendala berupa suatu pertidaksamaan adalah suatu hal yang perlu dipelajari lebih lanjut dalam teori optimasi. Metode Karush-Kuhn-Tucker (KKT) adalah suatu metode untuk menentukan nilai optimum suatu fungsi dengan kendala berupa pertidaksamaan [5].

Prosedur menggunakan metode KarushKuhn-Tucker (KKT) dalam memecahkan suatu masalah optimasi dengan kendala berupa pertidaksamaan, langkahnya sama halnya dengan menggunakan metode Lagrange untuk memecahkan masalah optimasi dengan kendala berupa suatu persamaan yaitu:

1. Membentuk suatu fungsi 'Lagrangian' $L$, maka dapat menghitung titik-titik kritisnya dan menguji nilai fungsi objektif pada setiap titik kritis yang memuat fungsi objektif optimal. Jadi dalam hal ini dibentuk suatu fungsi Lagrange yang didefinisikan dengan:

$$
L(X, \lambda)=f(X)+\sum_{i=1}^{l} \lambda_{i} h_{i}(X)
$$

2. Mencari semua solusi $(x, \lambda)$ dalam himpunan persamaan berikut:

$$
\frac{\partial L}{\partial x_{j}}(x, \lambda)=0 \quad ;(j=1,2, \ldots, n)
$$

dengan

$$
\begin{gathered}
\frac{\partial L}{\partial \lambda_{i}}(x, \lambda) \geq 0 \quad ; \quad \lambda_{i} \geq 0 \\
\lambda_{i} \frac{\partial L}{\partial \lambda_{i}}(x, \lambda)=0 \quad ; i=1,2 \ldots l
\end{gathered}
$$

Penyelesaian dari setiap sistem persamaan ini, selanjutnya disebut titik kritis dari $L$. Selanjutnya misalkan $M$ menotasikan himpunan titik-titik kritis yaitu $M=\{(x, \lambda) \mid(x, \lambda)$ adalah titik kritis dari $L\}$.

3. Langkah terakhir yaitu menghitung nilai dari $f$ untuk setiap titik kritis yang merupakan himpunan bagian dari $M$, yang memuat fungsi tujuan menjadi optimum. 


\section{METODE PENELITIAN}

Sumber data dalam penelitian ini diperoleh dari data sekunder, yaitu melalui dokumendokumen yang terdapat pada toko Novala Busana dan toko Trans Collection periode 1 tahun (1 April 2014 - 31 Maret 2015). Dalam penelitian ini, variabel yang digunakan adalah jenis kain endek dan harga kain endek. Untuk variabel jenis kain endek yaitu kain endek mastuli $\left(x_{1}\right)$, kain endek rangrang $\left(x_{2}\right)$, kain endek saraswati $\left(x_{3}\right)$, kain endek gradasi $\left(x_{4}\right)$, dan kain endek alam $\left(x_{5}\right)$. Sedangkan untuk variabel harga kain endek yaitu harga modal kain endek dan harga jual kepada konsumen.

Langkah-langkah yang digunakan dalam metode penelitian ini adalah:

1. Penyajian data penjualan masing-masing toko.

2. Menentukan variabel keputusan

3. Menentukan fungsi tujuan

4. Menentukan fungsi batasan

5. Mempartisi menjadi 4 bagian (Triwulan)

6. Optimalisasi KKT dengan bantuan software Matlab

\section{HASIL DAN PEMBAHASAN}

Berdasarkan jenis-jenis kain endek yang diteliti penjualannya pada toko Novala Busana dan toko Trans Collection, dapat ditentukan variabel keputusan, yaitu:

$x_{1}=$ Jumlah penjualan kain endek mastuli (pcs)

$x_{2}=$ Jumlah penjualan kain endek rangrang (pcs)

$x_{3}=$ Jumlah penjualan kain endek saraswati (pcs)

$x_{4}=$ Jumlah penjualan kain endek gradasi (pcs)

$x_{5}=$ Jumlah penjualan kain endek alam (pcs)

Tujuan yang ingin dicapai dalam penelitian ini adalah untuk mencapai keuntungan maksimum pada setiap jenis kain endek. Keuntungan diperoleh dari selisih antara harga modal dan harga jual kepada konsumen. Koefisien dari masing-masing variabel keputusan menunjukan keuntungan dari setiap jenis kain endek.
Fungsi tujuan Toko Novala Busana

$$
\begin{aligned}
f(x)= & 75.000 x_{1}+50.000 x_{2} \\
& +65.000 x_{3}+50.000 x_{4} \\
& +25.000 x_{5}
\end{aligned}
$$

Fungsi tujuan Toko Trans Collection

$$
\begin{aligned}
f(x) & =90.000 x_{1}+60.000 x_{2} \\
& +60.000 x_{3}+50.000 x_{4} \\
& +30.000 x_{5}
\end{aligned}
$$

Selanjutnya adalah menentukan fungsi batasan. Fungsi batasan dibentuk berdasarkan peluang masing-masing produk yang terjual terhadap total produk yang disediakan pada masing-masing toko. Periode waktu yang digunakan selama 1 tahun yang dipartisi menjadi 4 bagian, setiap bagian terdiri dari 3 bulan (triwulan). Bentuk baku fungsi batasannya yaitu:

Fungsi Batasan Toko Novala Busana

Triwulan I (April, Mei, Juni)

$$
\begin{gathered}
0,342 x_{1}+0,187 x_{2}+0,219 x_{3} \\
+0,327 x_{4}+0,362 x_{5} \leq 240 \\
x_{1}+x_{2}+x_{3}+x_{4}+x_{5} \leq 840 \\
x_{1}, x_{2}, x_{3}, x_{4}, x_{5} \geq 0
\end{gathered}
$$

Triwulan II (Juli, Agustus, September)

$$
\begin{gathered}
0,308 x_{1}+0,200 x_{2}+0,167 x_{3} \\
+0,360 x_{4}+0,314 x_{5} \leq 222 \\
x_{1}+x_{2}+x_{3}+x_{4}+x_{5} \leq 840 \\
x_{1}, x_{2}, x_{3}, x_{4}, x_{5} \geq 0
\end{gathered}
$$

Triwulan III (Oktober,November,Desember)

$$
\begin{gathered}
0,300 x_{1}+0,213 x_{2}+0,219 x_{3} \\
+0,540 x_{4}+0,376 x_{5} \leq 274 \\
x_{1}+x_{2}+x_{3}+x_{4}+x_{5} \leq 840 \\
x_{1}, x_{2}, x_{3}, x_{4}, x_{5} \geq 0
\end{gathered}
$$

Triwulan IV (Januari, Februari, Maret)

$0,300 x_{1}+0,247 x_{2}+0,348 x_{3}$

$+0,487 x_{4}+0,443 x_{5} \leq 312$

$x_{1}+x_{2}+x_{3}+x_{4}+x_{5} \leq 840$

$$
x_{1}, x_{2}, x_{3}, x_{4}, x_{5} \geq 0
$$

Fungsi Batasan Toko Trans Collection

Triwulan I (April, Mei, Juni)

$$
\begin{gathered}
0,300 x_{1}+0,193 x_{2}+0,186 x_{3} \\
+0,260 x_{4}+0,276 x_{5} \leq 210 \\
x_{1}+x_{2}+x_{3}+x_{4}+x_{5} \leq 840 \\
x_{1}, x_{2}, x_{3}, x_{4}, x_{5} \geq 0
\end{gathered}
$$

Triwulan II (Juli, Agustus, September)

$$
\begin{gathered}
0,300 x_{1}+0,200 x_{2}+0,167 x_{3} \\
+0,287 x_{4}+0,267 x_{5} \leq 200 \\
x_{1}+x_{2}+x_{3}+x_{4}+x_{5} \leq 840 \\
x_{1}, x_{2}, x_{3}, x_{4}, x_{5} \geq 0
\end{gathered}
$$

Triwulan III (Oktober,November,Desember)

$$
\begin{gathered}
0,267 x_{1}+0,213 x_{2}+0,167 x_{3} \\
+0,360 x_{4}+0,338 x_{5} \leq 224
\end{gathered}
$$




$$
\begin{gathered}
x_{1}+x_{2}+x_{3}+x_{4}+x_{5} \leq 840 \\
x_{1}, x_{2}, x_{3}, x_{4}, x_{5} \geq 0
\end{gathered}
$$

Triwulan IV (Januari, Februari, Maret)

$$
\begin{gathered}
0,275 x_{1}+0,240 x_{2}+0,238 x_{3} \\
+0,387 x_{4}+0,371 x_{5} \leq 225 \\
x_{1}+x_{2}+x_{3}+x_{4}+x_{5} \leq 840 \\
x_{1}, x_{2}, x_{3}, x_{4}, x_{5} \geq 0
\end{gathered}
$$

Setelah menentukan variabel keputusan, memodelkan fungsi tujuan dan fungsi batasan maka membetuk Lagrangian untuk menghitung titik-titik kritisnya, dan langkah selanjutnya memaksimumkan $f(X)$ dengan syarat:

$$
\begin{array}{cc}
\frac{\partial f}{\partial x_{i}}+\sum_{j=1}^{m} \lambda_{j} \frac{g_{j}}{\partial x_{i}}=0, & (i=1,2 \ldots, 5) \\
\lambda_{j} g_{j}=0, & (j=1,2,3) \\
g_{j} \leq 0, & (j=1,2,3) \\
\lambda_{j} \leq 0, & (j=1,2,3)
\end{array}
$$

Untuk mempermudah perhitungan dalam mencari masing-masing nilai $X$ digunakan software Matlab, diperoleh nilai $x_{1}=455.6098, \quad x_{2}=0.0000, \quad x_{3}=$ $384.3902, x_{4}=0.0000, \quad x_{5}=0.0000$. Hasil tersebut menunjukan bahwa toko Novala Busana dalam triwulan I akan mencapai keuntungan maksimum apabila terjual kain endek mastuli $\left(x_{1}\right)$ sebanyak 456 pcs dan endek saraswati $\left(x_{3}\right)$ sebanyak 384 pcs, dengan mencapai keuntungan maksimum yaitu sebesar Rp 59.156.000. Dengan langkah yang sama seperti pada triwulan 1, maka hasil yang diperoleh untuk triwulan 2,3,4 apabila dibentuk tabel maka hasilnya:

Tabel 1. Keuntungan Maksimum Triwulan Toko Novala Busana

\begin{tabular}{|c|c|c|c|c|c|c|}
\hline $\begin{array}{c}\text { Tri } \\
\text { Wulan }\end{array}$ & $\begin{array}{c}x_{1} \\
(\mathrm{pcs})\end{array}$ & $\begin{array}{c}x_{2} \\
(\mathrm{pcs})\end{array}$ & $\begin{array}{c}x_{3} \\
(\mathrm{pcs})\end{array}$ & $\begin{array}{c}x_{4} \\
(\mathrm{pcs})\end{array}$ & $\begin{array}{c}x_{5} \\
(\mathrm{pcs})\end{array}$ & $\begin{array}{c}\text { Keuntungan } \\
(\mathrm{Rp})\end{array}$ \\
\hline I & 456 & 0 & 384 & 0 & 0 & 59.156 .000 \\
\hline II & 580 & 0 & 260 & 0 & 0 & 60.396 .000 \\
\hline III & 840 & 0 & 0 & 0 & 0 & 63.000 .000 \\
\hline IV & 840 & 0 & 0 & 0 & 0 & 63.000 .000 \\
\hline
\end{tabular}

Hasil tersebut menunjukan bahwa triwulan I dan triwulan II sebaiknya sebagian besar menjual kain endek mastuli $\left(x_{1}\right)$ dan kain endek saraswati $\left(x_{3}\right)$. Pada triwulan III dan triwulan IV toko Novala Busana cukup dengan memaksimalkan penjualan kain endek mastuli $\left(x_{1}\right)$, maka toko telah memperoleh keuntungan maksimum.

Menentukan nilai optimum pada triwulan I toko Trans Collection, untuk mencari masing-masing nilai $x$ digunakan software Matlab untuk mempermudah perhitungan, sehingga diperoleh nilai $x_{1}=392.6316$, $x_{2}=0.000, x_{3}=447.3684, x_{4}=0.0000, x_{5}=$ 0.0000 .

Sehingga Toko Trans Collection dalam triwulan I akan mencapai keuntungan maksimum apabila terjual kain endek mastuli $\left(x_{1}\right)$ sebanyak 393 pcs dan endek saraswati $\left(x_{3}\right)$ sebanyak 447 pes dengan keuntungan maksimum yaitu sebesar Rp 62.179.000. Dengan langkah yang sama seperti pada triwulan I, maka hasil yang diperoleh untuk triwulan II, III, IV apabila dibentuk tabel maka hasilnya:

Tabel 2. Keuntungan Maksimum Triwulan Toko Trans Collection

\begin{tabular}{|c|l|l|l|l|l|l|}
\hline $\begin{array}{c}\text { Tri } \\
\text { wulan }\end{array}$ & $\begin{array}{c}x_{1} \\
(\mathrm{pcs})\end{array}$ & $\begin{array}{c}x_{2} \\
(\mathrm{pcs})\end{array}$ & $\begin{array}{c}x_{3} \\
(\mathrm{pcs})\end{array}$ & $\begin{array}{c}x_{4} \\
(\mathrm{pcs})\end{array}$ & $\begin{array}{c}x_{5} \\
(\mathrm{pcs})\end{array}$ & $\begin{array}{c}\text { Keuntungan } \\
(\mathrm{Rp})\end{array}$ \\
\hline I & 393 & 0 & 477 & 0 & 0 & 62.179 .000 \\
\hline II & 499 & 0 & 390 & 0 & 0 & $63,871.000$ \\
\hline III & 837 & 0 & 3 & 0 & 0 & 75.516 .000 \\
\hline IV & 840 & 0 & 0 & 0 & 0 & 75.600 .000 \\
\hline
\end{tabular}

Toko Trans Collection pada keempat triwulan periode 1 April 2014 sampai dengan 31 Maret 2015, hasil yang diperoleh menunjukkan bahwa triwulan I, triwulan II dan triwulan III sebaiknya sebagian besar menjual kain endek mastuli $\left(x_{1}\right)$ dan kain endek saraswati $\left(x_{3}\right)$. Sedangkan pada triwulan IV toko Trans Collection cukup dengan memaksimalkan penjualan kain endek mastuli $\left(x_{1}\right)$, maka toko telah memperoleh keuntungan maksimum.

\section{KESIMPULAN DAN SARAN}

Pada penelitian ini diperoleh kesimpulan yaitu, toko Novala Busana berdasarkan triwulan I dan II jenis kain endek yang dijual sebagian 
besar adalah endek mastuli $\left(x_{1}\right)$ dan endek saraswati $\left(x_{3}\right)$ untuk mencapai keuntungan yang maksimum. Sedangkan pada triwulan III dan IV yang dijual sebagian besar adalah kain endek mastuli $\left(x_{1}\right)$. Keuntungan terbesar, terlihat pada triwulan III dan IV yaitu sebesar Rp. 63.000.000.

Pada toko Trans Collection berdasarkan triwulan I, II, dan III jenis kain endek yang dijual sebagian besar adalah endek mastuli $\left(x_{1}\right)$ dan endek saraswati $\left(x_{3}\right)$. Sedangkan pada triwulan IV produk yang dijual sebagian besar adalah kain endek mastuli. Keuntungan terbesar, terlihat pada triwulan IV yaitu sebesar Rp. 75.600 .000 .

Hasil penelitian menunjukan sebagian besar yang harus dijual adalah jenis kain endek mastuli untuk mencapai keuntungan yang maksimum, akan tetapi pada kasus kehidupan dunia nyata, setiap individu belum tentu menyukai satu jenis kain endek yang sama. Dengan demikian disarankan untuk masingmasing toko, bukan berarti jenis kain endek lain tidak mesti dijual melainkan tetap tersediakan walaupun tidak sebanyak sebelumnya. Pada penelitian selanjutnya diharapkan dapat melibatkan variabel yang lebih bervariasi dengan kasus yang lebih menarik.

\section{DAFTAR PUSTAKA}

[1] A. Taha, H. 1996. Riset Operasi. Terjemahan Daniel Wirajaya. Jakarta: Penerbit Binarupa Aksara.

[2] Amalia. 2010. Peranan Persyaratan Karush-Kuhn-Tucker dalam Menyelesaikan Pemrograman Kuadratis. Skripsi. Universitas Sumatra Utara. http://repository.usu.ac.id/bitstream/12345 6789/14099/1/10E00011.pdf. Diakses tanggal 3 Februari 2015.

[3] Luknanto, D. 2000. Pengantar Optimasi Non Linier. Yogyakarta: UGM. hhtp://luk.Staff.Ugm.ac.id/Optimasi/pdf/no nlinier2003/.pdf. (Diunduh 2 Februari 2015).

[4] Purcell, E. J., Varberg, D., \& Rigdon, S. E. 2004. Kalkulus. Edisi Kedelapan Terjemahan Julian Gressando. Jakarta: Penerbit Erlangga.

[5] Rao, S. S. 1984. Optimization Theory and Applications. Second Edition. USA: Dept. of Mechanical Engg. San Diego State University. 